\title{
AN AHP MODEL FOR LEVEL CROSSING DESIGN
}

\author{
DANIJELA BARIĆ \& FILIP PIŽETA \\ University of Zagreb, Faculty of Transport and Traffic Sciences, Zagreb, Croatia.
}

\begin{abstract}
Level crossings (LCs) are places of rail and road intersections, and therefore, areas with increased risk of severe accidents. The main objective of this study is to apply the multi-criteria Analytical Hierarchy Process (AHP) method to evaluate the variants for the reconstruction of LCs in an urban environment through weighting of various criteria and sub-criteria. The research methodology is applied on LC Trnava in Zagreb. Four developed variants are presented and evaluated with AHP method. For applying the AHP method the Expert Choice software package has been used. Simulation of the current state and optimal variant is made in PTV VISSIM. This approach may prove useful by the AHP method for evaluating and selecting the appropriate LC designs.
\end{abstract}

Key words: AHP, level crossings, safety.

\section{INTRODUCTION}

From the safety point of view, level crossings (LCs) are critical points in the safe conduct of rail and road traffic. According to statistics, the main cause for all accidents (more than 95\%) is human factor of road users (drivers, cyclist and pedestrians) who did not follow and obey the traffic safety regulations at level crossings [1].

Traffic safety and use of alternative modes of transport are the main problems in the big cities all over the world. To solve these problems the measures and procedures are used, which improve the quality of the mobility of traffic system users in a modern and environmentally sustainable way. In this paper, we have analysed the traffic flows at the level crossing Trnava. The main problems for the low state of safety at the level crossing are the failure to comply with traffic rules and regulations and low level of traffic culture among the participants. Also, there is a problem of bad traffic connection, which limits the mobility of users. As solutions for these problems we have proposed new project solutions with the goal of increasing the safety and mobility of users in the area of the level crossing Trnava. For the evaluation of the proposed variants and the optimal project solution it is necessary to apply one of the multi-criteria decision-making methods (MCDM) and a simulation of the condition before and after reconstruction.

The main purpose of the study is to describe and analyse the current state of the LC Trnava in Zagreb (Croatia), propose new variants for reconstruction, build AHP model, evaluate variants by multi-criteria method AHP and eventually, according to AHP method results, select the optimal design solution of LC for the reconstruction. Based on the previous explanation this research is supposed to answer what are the main factors (criteria and sub-criteria) that effect on choosing the best variant for LC design.

\section{METHODOLOGY}

Numerous multi-criteria models have been applied to socially important investment projects [2], especially traffic infrastructure projects [3-5]. These methods differ primarily in their optimisation criteria, which always involve a combination of technological, technical, ecological and other criteria. One of the most frequently used multi-criteria models is the Analytical Hierarchy Process (AHP) model [6]. The AHP model has proven valuable not just in traffic sciences [7] but also in most other spheres of human activities, including civil 
engineering [8, 9], marketing [10], entertainment [11] and the selection of academic staff [12]. In this paper AHP method has been applied.

With the aim of determining the optimal variant of LC, based on the applied AHP method, the methodology understands the following steps: (a) analysis of the current condition of LC Trnava (characteristics of the current traffic network, collection of real data about the size and distribution of the current traffic load, traffic count, survey of LC users, determining the drivers' habits, and their traffic culture, etc.); (b) development of simulation of the existing condition in the software tool PTV VISSIM; (c) proposal of new variants of reconstruction; (d) build an AHP model. Evaluation of the variants using AHP method with the application of the software tools Expert Choice (defining of the hierarchical structure of AHP model, ranking of criteria and sub-criteria, evaluation of variants, selection of the optimal variant); (e) development of simulation of the optimal variant in software tools PTV VISSIM.

Thomas Saaty developed the AHP method to guide complex multi-criteria decision-making problems. It can perform better than other multi-criteria methods because it can be easily adapted to different numbers of attributes (criteria) and alternatives, which can be described both quantitatively and qualitatively [13].

Based on the collected data, the survey method (200 surveys), traffic counts and recording of participant behaviour, there is an average of 53\% illegal crossing pedestrians and $51 \%$ illegal cycling crossings per day. Furthermore, $73 \%$ of respondents are not aware of dangerous of risky behaviour and do not know how much the penalty is for illegal crossing, which indicates that traffic participants are not sufficiently informed and do not understand the seriousness of improper crossing. It is also apparent that the half-barier has dropped nearly $50 \%$ of the time, leading to a long wait at the LC and thus improper crossing. Traffic participants believe that necessary changes are needed to ensure a greater level of safety for the participants and better connectivity and mobility of the population, while $93 \%$ of the respondents believe that the passageway and the underpass are a necessity.

\section{THE AHP MODEL TO LEVEL CROSSING DESIGN}

\subsection{Study Area and Problem}

The level crossing Trnava is located at the intersection of the Zagreb Main Railway Station - Dugo Selo (M102) railway line in KM 430+112 and non-classified roads in Zagreb. The M102 railway line is an international railway line of the highest rank and in such cases the recommendation is to avoid level crossings with other modes of transport. There are 199 trains passing daily along the line. The maximum running speed of the trains passing the section through Trnava is $140 \mathrm{~km} / \mathrm{h}$ [1]. Parallel to the railway line there is Branimirova Street which is one of the busiest streets in the city of Zagreb (Fig. 1).
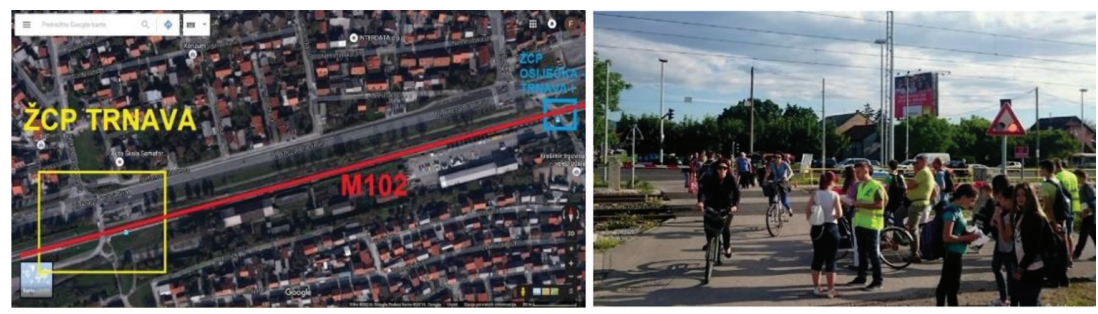

Figure 1: Study area LC Trnava. 
Apart from the significant traffic of motor vehicles there is a very intensive traffic of pedestrians and cyclists in the narrow area of LC Trnava with the aim of going to work, school, faculty, shopping, and other activities. In spite of high traffic load, the areas travelled by passenger cars, and pedestrians and cyclists have not been appropriately designed which additionally aggravates the safety of traffic participants. There is a lack of vertical and horizontal traffic signalisation for road traffic regulation, and also missing are the pedestrian and cyclist paths. A big problem of this LC lies also in the non-compliance of traffic rules and regulations by traffic participants. The pedestrians and cyclists cross the line illegally when the barrier is down. Although the railway-road crossing is secured by the highest security level (half-barriers and light-sound signalisation), by analysing the current state there has been a substantial number of traffic accidents with fatal consequences or large material damage. In the period since 2001, there were six traffic accidents at the LC Trnava in which seven persons were killed, and two were seriously injured [1].

In order to determine the model of the behaviour of pedestrians and cyclists at the LC Trnava, a survey was carried out on 2 June 2016 on a sample of 200 respondents. The survey consisted of nine short and clear questions with the priority of finding out the number of people who use the LC, how often they use it and whether they comply with the crossing regulations, and if not, why. Out of a total of 200 respondents $(55 \% \mathrm{~F}$ and $45 \% \mathrm{M})$, the highest number of respondents belonged to the group of 26-60 years of age (61\%); $84 \%$ of respondents use the LC Trnava every day, $61 \%$ live within $500 \mathrm{~m}$ of the LC, $73 \%$ of respondents do not know how much is the fine for illegal crossing, $33 \%$ of respondents indicate that the reason for illegal crossing is because they are in a hurry, and $93 \%$ of respondents think that it is necessary to build an underpass (for pedestrians and for vehicles). Asked about the reasons for legal and illegal crossing of the LC, $33 \%$ of respondents stated that they are in a hurry, $13 \%$ of respondents think it is safe to pass because they do not see any train arriving, $12 \%$ of respondents think that the barrier stays lowered for too long, $9 \%$ say that they are tired of waiting, $6 \%$ estimate that it is safe, and only $29 \%$ of respondents cross the LC in a proper and legal way [14].

\subsection{Simulation of the current state}

Microscopic simulation tool PTV VISSIM is used in order to analyse the current condition of the traffic flows in the area of LC Trnava and LC Osječka-Trnava I. The analysis included the traffic flows of motor vehicles and the still traffic with the aim of acquiring data about the length of queues at LC and how the lowered half-barriers and he ban on the passage of motor vehicles and pedestrians influence the throughput capacity of the traffic flows. The coverage area for the simulation is presented in Fig. 2. The simulation has been done on the basis of the input data about the traffic load, collected by the traffic count.

The longest queues are formed on the Branimirova Street in the East-West direction. The queues have been presented in metres and amount to 240.8 metres which is about 40 vehicles. At this approach also the largest average vehicle delays have been recorded, and they amount to 26.06 seconds and the longest average waiting of vehicles in the amount of 19.8 seconds. The highest emission of harmful $\mathrm{CO}$ gases has been recorded at this approach in the direction towards the centre and it amounts to 932.103 PPM and northwards in the amount of 899.611 PPM. This is followed by the approach of Branimirova Street in the direction from West towards North and it amounts to 549.051 PPM. The highest consumption of fuel has been recorded on the east transit on the Branimirova Street amounting to 13.335 litres followed by the West approach of the Branimirova Street for left turners northwards, whose average fuel consumption amounts to 7.855 litres (Table 1). 


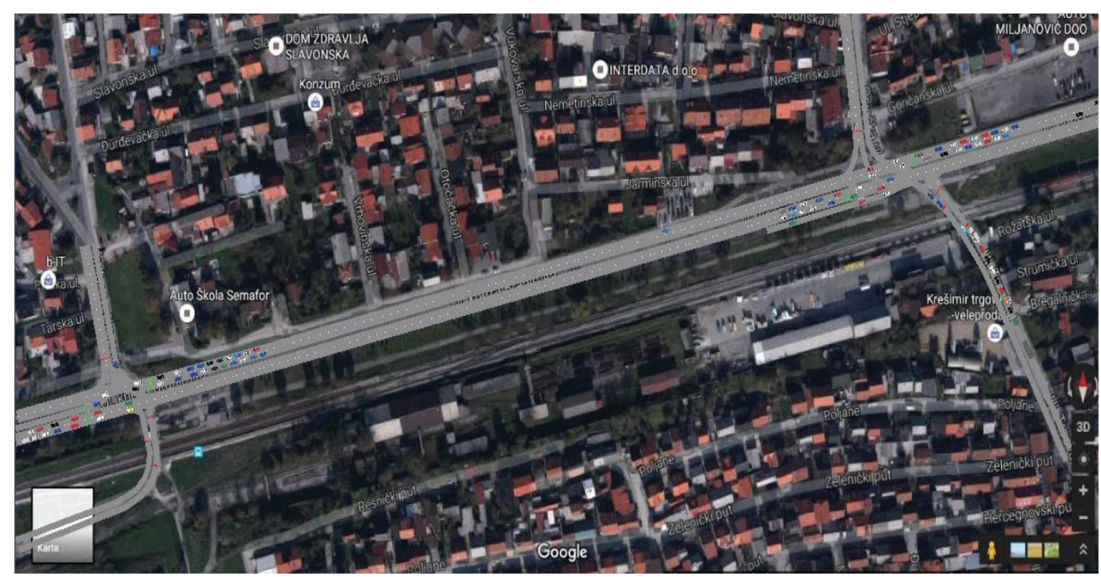

Figure 2: Simulation of the current state at LC Trnava and LC Osječka-Trnava I in PTV VISSIM.

Table 1: The results of the simulation of the current condition at LC Trnava (PTV Vissim).

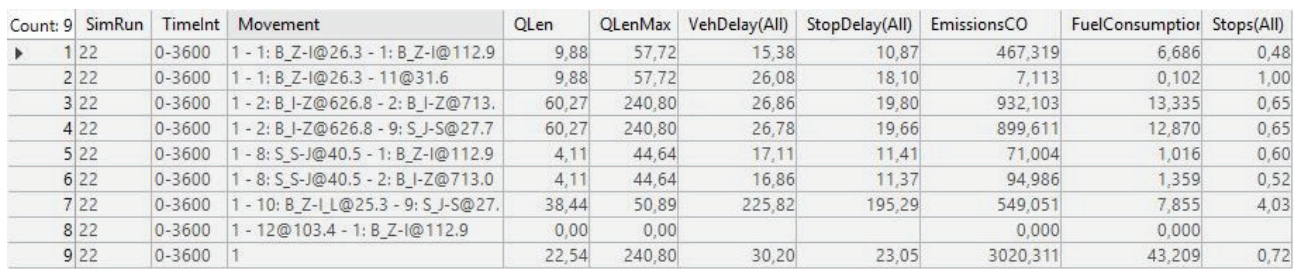

Forming of queues is noticeable from the Trnava I Street and on the Branimirova Street in the West-South direction (right turners on Branimirova Street). The length of queues from Trnava I Street amounts to 143.92 metres, which is about 24 vehicles, and the length of the queues in Branimirova Street in the direction from West to South (right turners) amounts to 33.88 metres which is on the average about 6 vehicles. The largest delay of vehicles has been recorded on the south approach of Trnava I Street which amounts to 80.44 seconds and the longest waiting in the amount of 69.7 seconds. The largest emission of harmful CO gases has been recorded in the Branimirova Street in the East-West direction in the amount of 1,182.821 PPM. At this approach also the highest fuel consumption has been recorded in the amount of almost 17 litres (Table 2) [14].

Table 2: The results at LC Osječka-Trnava I (PTV Vissim).

\begin{tabular}{|c|c|c|c|c|c|c|c|c|c|c|}
\hline Count: 9 & 9 SimRun & Timelnt & Movement & QLen & QLenMax & VehDelay(All) & StopDelay(All) & Emissions $\mathrm{CO}$ & FuelConsumptiot & Stops(All) \\
\hline \multirow[t]{6}{*}{ 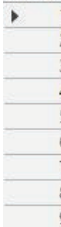 } & 126 & $0-3600$ & 1-1:B_Z-1@547.6 - 1: B_Z-1@664. & 11,53 & 63,51 & 15,75 & 11,71 & 667,714 & 9,552 & 0,45 \\
\hline & 226 & $0-3600$ & 1-2:B_I-Z@75.8-2:B_I-Z@193.7 & 24,49 & 133,60 & 18,27 & 11,41 & 1182,821 & 16,922 & 0,56 \\
\hline & 326 & $0-3600$ & 1-2:B_I-Z@75.8-7:0_J-S@42.3 & 24,49 & 133,60 & 19,58 & 12,88 & 45,751 & 0,655 & 0,57 \\
\hline & 526 & $0-3600$ & 1-5:T_J-S@136.7-1:B_Z-1@664. & 52,77 & 143,92 & 80,44 & 69,70 & 53,172 & 0,761 & 0,96 \\
\hline & 626 & $0-3600$ & 1-5:T_J-S@136.7-2:B_I-Z@193. & 52,77 & 143,92 & 76,11 & 64,86 & 592,377 & 8,475 & 0,98 \\
\hline & 726 & $0-3600$ & 1-6: O_S-J@60.3 - 1: B_Z-I@664.2 & 4,36 & 37,39 & 17,71 & 12,17 & 59,631 & 0,853 & 0,66 \\
\hline
\end{tabular}




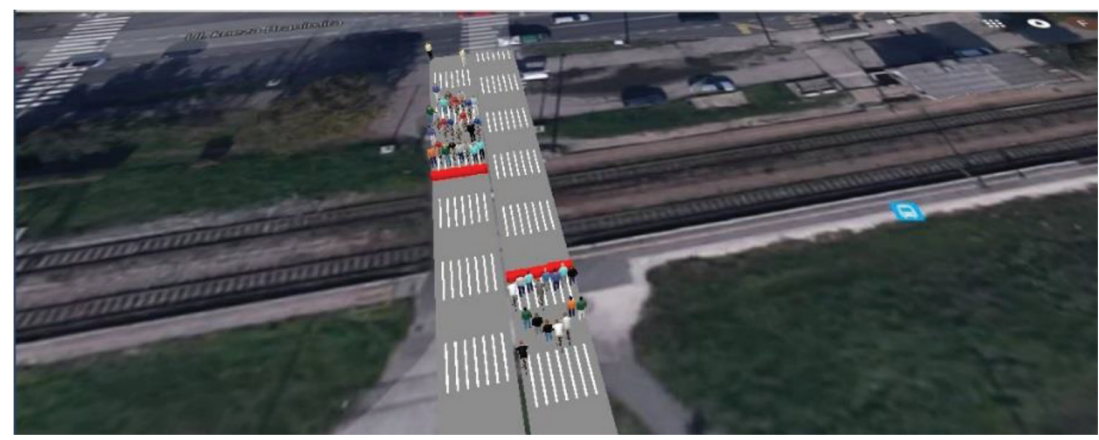

Figure 3: The intensity of pedestrian and cyclist traffic at LC Trnava (PTV VISSIM).

The intensity of pedestrian and cyclist flows at LC Trnava has been presented in Fig. 3. The simulation has been performed with the assumption that all the users comply with the traffic rules and regulations in order to get real data about the average time of delay and waiting of the users.

In spite of the half-barriers being lowered, almost $50 \%$ of the time the average waiting time of the users depends on the distribution of their arrival to the LC. Thus, the following results have been obtained: the number of persons arriving and waiting at LC is 20 users from the North and 31 from the South, the average delay of users is 51.5 seconds and the average waiting time is 48.03 seconds (Table 3 ).

\subsection{Proposal of new variants}

In order to improve the level of traffic safety and capacity, four possible variant designs for reconstruction are proposed.

\section{Variant 1}

The proposal of the design solution Variant 1 is the construction of a pedestrian-cyclist underpass (Fig. 4a). The construction of an underpass would eliminate the conflict points between the road and rail traffic, i.e. primarily of pedestrians and cyclists and the rail vehicles.

\section{Variant 2}

The proposal of the design solution Variant 2 is the construction of a pedestrian-cyclist underpass the same as in the previous variant and the construction of an approach road towards the warehouse from the direction of Trnava and ban on the movement of road vehicles from the Branimirova Street towards LC. The ban on road vehicles is stated by a traffic sign of explicit ban and with a mounted protective fence that prevents violation of traffic regulations by the drivers (Fig. 4b).

Table 3: The results of the pedestrian and cyclist traffic at LC Trnava (PTV Vissim).

\begin{tabular}{|c|c|c|c|c|c|c|c|c|c|c|c|}
\hline Count: 3 & SimRun & Timelnt & Movement & QLen & QLenMax & Vehs(All) & Pers(All) & VehDelay(All) & PersDelay(All) & StopDelay(All) & Stops(All) \\
\hline 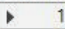 & 8 & $0-3600$ & 1-1: S-J@6.2 -1: S-J@40.9 & 7,34 & 20,37 & 418 & 418 & 51,50 & 51,50 & 47,74 & 0,60 \\
\hline & 8 & $0-3600$ & 1-2:J-S@17.8-2:J-S@52. & 9,97 & 31,11 & 405 & 405 & 51,16 & 51,16 & 48,03 & 0,57 \\
\hline & 8 & $0-3600$ & 1 & 8,65 & 31,11 & 823 & 823 & 51,33 & 51,33 & 47,88 & 0,58 \\
\hline
\end{tabular}




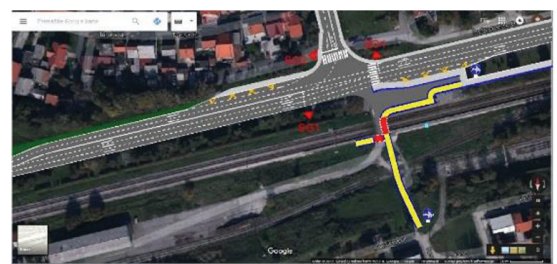

(a)

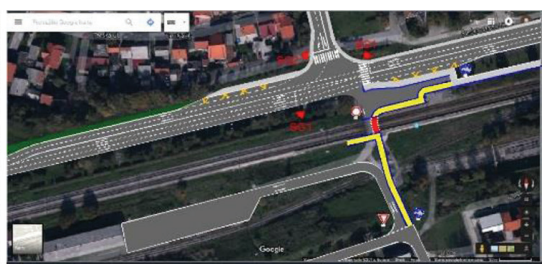

(b)

Figure 4: Variants 1 and 2 (a) Variant 1; (b) Variant 2.

\section{Variant 3}

Variant 3 means reconstruction of two adjacent LCs, LC Trnava and LC Osječka-Trnava I, at a distance of 500 metres between them (Fig. 5). This design solution proposes the construction of the underpass for the pedestrians and cyclists and the construction of an underpass for the drivers from Trnava who merge into the Branimirova Street eastwards (right turners) and westwards (left turners). Also, the construction of an underpass for the right turners from the Branimirova Street towards Trnava is proposed.

\section{Variant 4}

The proposal of the design solution Variant 4 is a combination of the proposal for the solution in Variant 2 and Variant 3. This proposal of the solution for the level crossing of Trnava and Osječka-Trnava I insures high safety level of the traffic flow. It completely eliminates the conflict points between the road vehicles and pedestrians, road vehicles and rail vehicles, and the pedestrians and rail vehicles at the mentioned LC (Fig. 6). The construction costs of these design solutions are somewhat lower than for the construction of elements from the previous variant. For the realisation of the mentioned design solutions less space is necessary for the construction than for the construction of the elements from the previous variant.

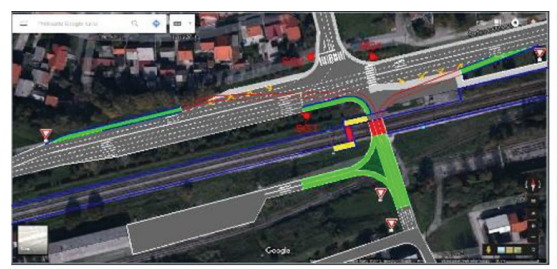

(a)

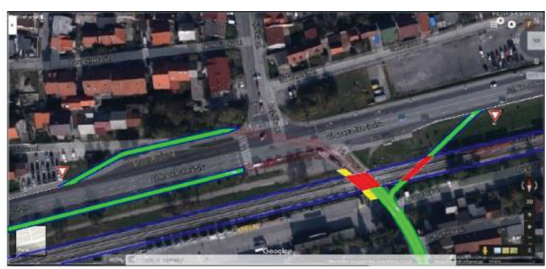

(b)

Figure 5: Variant 3 (a) LC Trnava; (b) LC Trnava I.

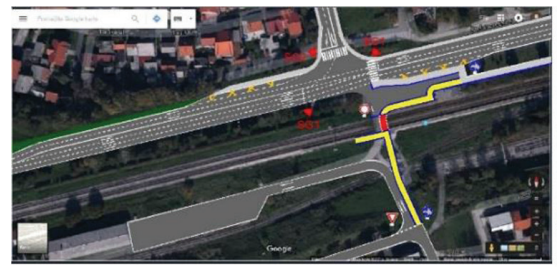

(a)

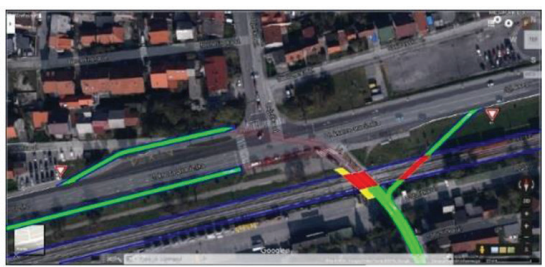

(b)

Figure 6: Variant 4 (a) LC Trnava; (b) LC Trnava I. 


\subsection{The AHP model}

The hierarchical structure of every AHP model consists of: objective, criteria, sub-criteria and variants. The evaluation of the proposed design solutions using the AHP method with the application of the software tool Expert Choice is performed on the basis of the defined criteria and their sub-criteria. The proposed criteria with the respective sub-criteria in order to evaluate the variants are presented in the hierarchical structure of the AHP model (Fig. 7).

\subsection{Results}

After the problem has been structured, there comes the process of ranking the criteria and sub-criteria, followed by the evaluation of the variants according to each criterion and sub-criterion.

Because of serious consequences brought by the traffic accidents on the railway-road crossings, the criterion 'Safety at LC Trnava' has been allocated the highest importance. The second important is the criterion 'Social benefits' due to all the advantages brought by the improvement of the traffic system thus raising the quality of the mobility of the society. The financial indicators are the third criterion regarding importance in order to invest financial means rationally in relation to the obtained benefits. Of the same importance are the ecological indicators due to the importance of adapting to the standards of environmental protection and stimulation of using the environmentally-friendly transport modes. The fifth important criterion is the 'Functional efficiency', which refers to the improvement of the parameters that affect the traffic flow. Of the same importance is the technical-technological criterion that refers to the construction of the essential road elements. The last in importance is the spatialurban criterion because of the possibility of the implementation of the advanced solutions that occupy relatively little space, and blend nicely into the environment (Fig. 8).

After having ranked the criteria, the sub-criteria were ranked as part of each criterion (Figs. 9-15).

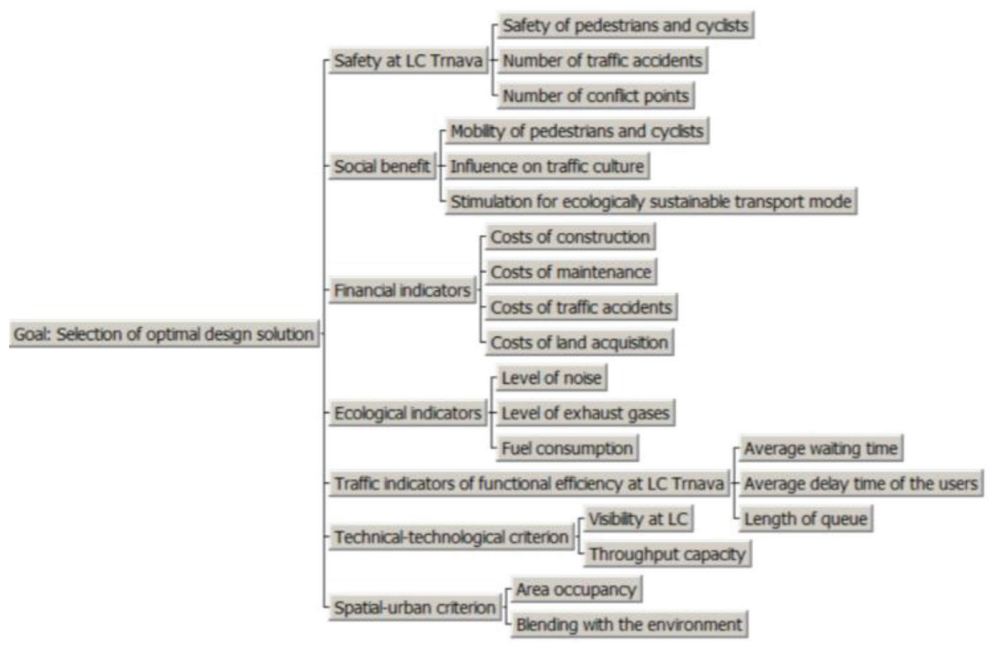

Figure 7: Hierarchical structure of AHP model. 


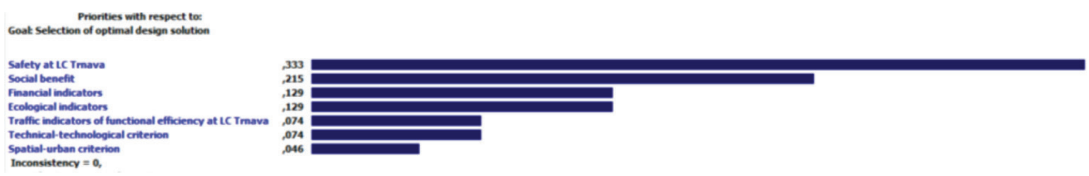

Figure 8: Ranking of criteria.
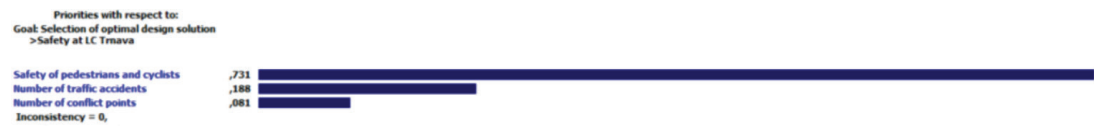

Figure 9: Ranked sub-criteria of the criterion 'Safety at LC Trnava'.

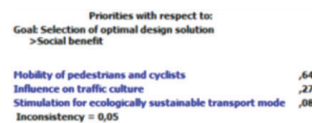

Figure 10: Ranked sub-criteria of the criterion 'Social benefits'.
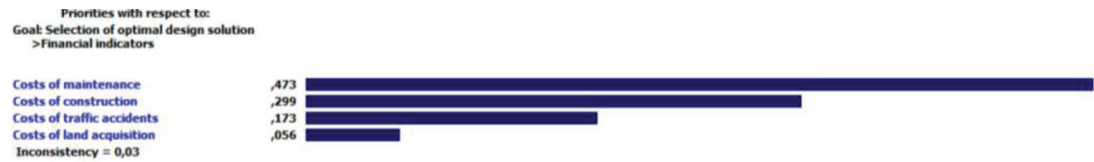

Figure 11: Ranked sub-criteria of the criterion 'Financial indicators'.

Priorities with respect to: oaat Selection of optimal design solution

Level of noise Level of exhaust gases Fuel consumption

, 400 Inconsistency $=0$,

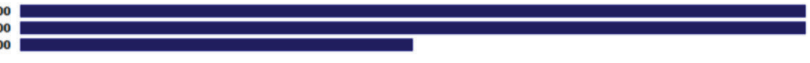

Figure 12: Ranked sub-criteria of the criterion 'Ecological indicators'.
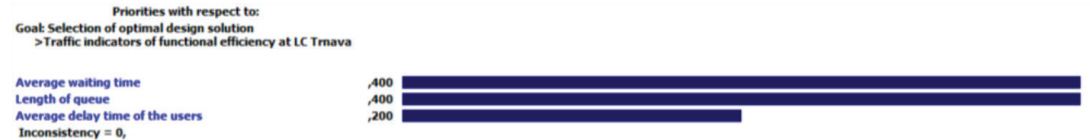

Figure 13: Ranked sub-criteria of the criterion 'Traffic indicators of the functional efficiency of LC'.

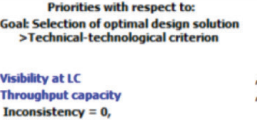

Figure 14: Ranked sub-criteria of the criterion 'Technical - technological'. 


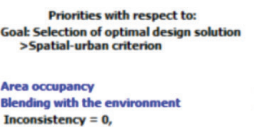

Figure 15: Ranked sub-criteria of the criterion 'Spatial - urban'.

Synthesis with respect to: Goal: Izbor optimalnog projektnog rjesenja

Overall Inconsistency $=, 01$

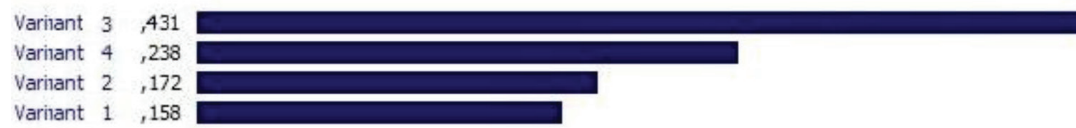

Figure 16: Ranking of the variants.

After performing the entire analysis and evaluation of the variants according to each criterion and sub-criterion using AHP method Variant 3 (43.1\%) has been proposed as the best traffic solution, and it includes a number of functional traffic solutions to increase the safety and urban mobility of the LC Trnava region. It is followed by Variant 4 (23.8\%), Variant 2 (17.2\%), and Variant 1 (15.8\%), showed on Fig. 16.

\section{SIMULATION OF OPTIMAL VARIANT IN SOFTWARE TOOL PTV VISSIM}

The values of the resulting parameters of the future condition of motor traffic flow at LC Trnava are presented in Table 4. It may be noted that the queues have been reduced to a minimum in relation to the current state. The longest queue is formed in Štefanovečka Road for vehicles that merge into Branimirova Street eastwards (left turners), and it is 38.35 metres long which is about 6 vehicles. Then in Branimirova Street for left turners from West towards North, which is 19.73 metres long, which is about three vehicles. In spite of the forming of queues their average delay amounts to 15 seconds which is negligible in relation to the current state. The highest $\mathrm{CO}$ emission has been recorded in case of vehicles that drive along the Branimirova Street from the East towards the West and amounts to 578.335 PPM which is half of the current state. Also, in this direction the highest fuel consumption has been recorded, amounting to 8.27 litres which is half of the quantity spent in the current state.

Table 4: The results of the future situation at LC Trnava (PTV Vissim).

\begin{tabular}{|c|c|c|c|c|c|c|c|c|c|c|}
\hline Count: 9 & SimRun & Timelnt & Movement & QLen & QLenMax & VehDelay(All) & StopDelay(AII) & Emissions $\mathrm{CO}$ & FuelConsumptiol & Stops(All) \\
\hline$\checkmark$ & 8 & $0-3600$ & 1-1@94.2 & 0,00 & 0,00 & 0,01 & 0,00 & 295.705 & 4.230 & 0,00 \\
\hline 2 & 28 & $0-3600$ & 1-2@37.8 & 0,00 & 0,00 & 0,02 & 0,00 & 32.935 & 0.471 & 0,00 \\
\hline 3 & 8 & $0-3600$ & $1-3 @ 70.0$ & 1,07 & 19,73 & 15,87 & 8,98 & 70.529 & 1.009 & 0,79 \\
\hline 4 & 48 & $0-3600$ & 1 -4@66.9 & 0,00 & 0,00 & 0,20 & 0,00 & 578.335 & 8.274 & 0,00 \\
\hline 5 & 58 & $0-3600$ & 1 -4@66.9 & 0,00 & 0,00 & 0,48 & 0,00 & 10.091 & 0.144 & 0,00 \\
\hline 6 & 58 & $0-3600$ & 1-6@68.4 & 0,00 & 0,00 & 0,04 & 0,00 & 7.886 & 0.113 & 0,00 \\
\hline 9 & 98 & $0-3600$ & 1 & 0,50 & 38,35 & 1,25 & 0,55 & 1103.670 & 15.789 & 0,05 \\
\hline
\end{tabular}


Table 5: The results of the future situation at LC Osječka-Trnava I (PTV Vissim).

\begin{tabular}{|c|c|c|c|c|c|c|c|c|c|c|}
\hline Count: 8 & SimRun & Timelnt & Movement & QLen & QLenMax & VehDelay(All) & StopDelay(All) & EmissionsCO & FuelConsumptiot & Stops(All) \\
\hline$\checkmark$ & 2 & $0-3600$ & 1 - 1@84.0 & 0,00 & 0,00 & 0,05 & 0,00 & 365.126 & 5.224 & 0,00 \\
\hline 2 & 2 & $0-3600$ & 1-2@64.8 & 0,00 & 0,00 & 0,16 & 0,00 & 578.496 & 8.276 & 0,00 \\
\hline 3 & 2 & $0-3600$ & 1-2@64.8 & 0,00 & 0,00 & 0,37 & 0,00 & 7.132 & 0.102 & 0,00 \\
\hline 4 & 2 & $0-3600$ & 1-3@79.2 & 0,00 & 0,00 & 0,01 & 0,00 & 34.093 & 0.488 & 0,00 \\
\hline 5 & 2 & $0-3600$ & $1-4 @ 26.3$ & 0,00 & 0,00 & 0,28 & 0,00 & 6.035 & 0.086 & 0,00 \\
\hline 6 & 2 & $0-3600$ & $1-6 @ 15.3$ & 0,35 & 38,42 & 8,69 & 4,95 & 17.922 & 0.256 & 0,35 \\
\hline
\end{tabular}

The values of the resulting parameters of the future state of motor traffic flow at LC OsječkaTrnava I are presented in Table 5. It may be noted that the queues have been reduced to a minimum in relation to the existing state. The longest queue is formed in the Osječka Street for the vehicles that merge into the Branimirova Street eastwards (left turners) and amounts to 38.42 metres which is about six vehicles. In spite of the forming of queues their average delay amounts to nine seconds which is negligible in relation to the current state. At other approaches no queues have been recorded. The highest $\mathrm{CO}$ emission has been recorded in case of vehicles that move along Branimirova Street from the East to the West and amounts to 578.496 PPM which is half of the current state. Also, in this direction the highest fuel consumption has been recorded amounting to 8.27 litres which is half of the current state. The results about the highest $\mathrm{CO}$ emission and the average fuel consumption have been recorded precisely in the direction which experiences the highest load and has not been formed due to the queues.

\section{CONCLUSION}

The aim of the performing the method of the Analytical Hierarchy Process is the selection of the optimal design solution among the four proposed variants for the reconstruction of LC Trnava and LC Trnava I. The first variant includes the construction of the pedestrian/cyclist underpass at the location of LC Trnava and the respective pedestrian/cyclist paths. The second variant, apart from the already mentioned underpass, would include the approach road towards the warehouse from Trnava and the traffic of road motor vehicles across the LC Trnava would be banned. The third variant would include all of the already mentioned variants with the addition of an underpass for cars at LC Trnava and LC Osječka-Trnava I. The fourth variant proposes the construction of the pedestrian/cyclist underpass at LC Trnava and the traffic ban for road motor vehicles and proposes the construction of the underpass (for pedestrians, cyclists and cars) at LC Osječka-Trnava I.

The results of the performed method of Analytical Hierarchy Process show that the optimal selection is Variant 3 which is by $19.3 \%$ better than Variant 4, by $25.9 \%$ better than Variant 2 and by $27.2 \%$ better than Variant 1.

Based on the selection of the optimal variant the simulation of the future state has been developed as well as comparison with the current state. The results of the simulation say that the queue length was reduced from 240 metres to 38 metres, the average vehicle delay was reduced from 80 seconds to 16 seconds. The share of $\mathrm{CO}$ has been almost halved and amounts to 578 PPM. Also, the average fuel consumption decreased from 17 litres to 8.2 litres. By analysis of the pedestrian and cyclist flows no queues nor delays of the users have been recorded, because the construction of an underpass has been proposed which allows undisturbed crossing of LC and eliminating the conflict points with all motor vehicles. The 
underpasses proposed in the optimal Variant for the pedestrian and cyclist traffic allow undisturbed passage of the users across the LC with the highest level of safety. This method of solving the pedestrian-cyclist flows reduces to a great extent the travel time, completely eliminates the waiting time at LC, increases the travel comfort to the destination and provides the feeling of satisfaction stimulating them to use the environmentally friendly methods of transport in urban environments.

\section{ACKNOWLEDGEMENTS}

The research described in this paper was conducted within the scope of the project 'Implementacija mjera za povećanje sigurnosti najranjivijih sudionika u prometu na željezničko-cestovnim prijelazima' (Eng. Implementation of measures to improve the safety of the most vulnerable traffic participants at level crossings) performed as part of the National program of road traffic safety of the Republic of Croatia 2011-2020 of the Ministry of the Interior of the Republic of Croatia. The Faculty of Transport and Traffic Sciences University of Zagreb is the carrier of this project and HŽ Infrastructure is the project partner.

\section{REFERENCES}

[1] Implementation of measures to improve the safety of the most vulnerable traffic participants at level crossings, Internal data, Faculty of Transport and Traffic Sciences University of Zagreb, Department for Road Transport, Zagreb, 2017.

[2] Barić, D., Pilko, H. \& Strujić, J., An analytic hierarchy process model to evaluate road section design. Transport, 31(3), pp. 312-321, 2016.

https://doi.org/10.3846/16484142.2016.1157830

[3] Nowak, M., Investment projects evaluation by simulation and multiple criteria decision aiding procedure. Journal of Civil Engineering and Management, 11(3), pp. 193-202, 2005. https://doi.org/10.1080/13923730.2005.9636350

[4] Barić, D., Čurepić, D. \& Radačić, Ž., Implementation of relevant methods in assessing traffic-technological projects. Promet - Traffic\&Transportation, 19(5), pp. 329-336, 2007.

[5] Aghdaie, M.H., Hashemkhani Zolfani, S. \& Zavadskas, E.K., Prioritizing constructing projects of municipalities based on AHP and COPRAS-G: a case study about footbridges in Iran. The Baltic Journal of Road and Bridge Engineering, 7(2), pp. 145-153, 2012.

https://doi.org/10.3846/bjrbe.2012.20

[6] Podvezko, V., Application of AHP technique. Journal of Business Economics and Management, 10(2), pp. 181-189, 2009.

https://doi.org/10.3846/1611-1699.2009.10.181-189

[7] Saaty, T.L., Transport planning with multiple criteria: the analytic hierarchy process applications and progress review. Journal of Advanced Transportation, 29(1), pp. 81-126, 1995.

https://doi.org/10.1002/atr.5670290109

[8] Cerić, A., Marčić, D. \& Kovačević, M.S., Applying the analytic network process for risk assessment in sustainable ground improvement. GRAĐEVINAR, 65(10), pp. 919-929, 2013.

[9] Karleuša, B., Ožanić, N. \& Deluka-Tibljaš, A., Improving decision making in defining priorities for implementation of irritigation plans using AHP methodology. Tehnički vjesnik - Technical Gazette, 21(3), pp. 673-680, 2014. 
[10] Gholami, M.H. \& Seyyed-Esfahani, M., An integrated framework for competitive market strategy selection by using Fuzzy AHP. Tehnički vjesnik - Technical Gazette, 19(4), pp. 769-780, 2012.

[11] Vidal, L.A., Marle, F. \& Bocquet, J.C., Using a Delphi process and the Analytic Hierarchy Process (AHP) to evaluate the complexity of projects. Expert Systems with Applications, 38(5), pp. 5388-5405, 2011. https://doi.org/10.1016/j.eswa.2010.10.016

[12] Rouyendegh, B.D. \& Erkan, T.E., Selection of academic staff using the fuzzy analytic hierarchy process (FAHP): a pilot study. Tehnički vjesnik - Technical Gazette, 19(4), pp. 923-929, 2012.

[13] Saaty, T.L., Decision making with the analytic hierarchy process. International Journal of Services Sciences, 1(1), pp. 83-98, 2008. https://doi.org/10.1504/ijssci.2008.017590

[14] Pižeta, F., Project Variants Evaluation of Trnava Level Crossing by Applying Analytic Hierarchy Process, Master thesis, Faculty of Transport and Traffic Sciences University of Zagreb, Zagreb, 2016. 